\title{
Certification of Death: External Postmortem Examination
}

\section{Burkhard Madea and Antonella Argo}

\subsection{Introduction}

For the external postmortem examination, the physician has to fulfil a wide range of functions concerning different legal and social aspects (Table 6.1). These functions became part of the external postmortem examination in the 19th century and are described in the Royal Bavarian Instructions for Postmortem Examinations dated 6 October 1839 as follows:

The purpose of the examination after death is, firstly, to avoid the burial of those who merely appear to be dead, and, next, to prevent the concealment of violent death and medical bungling; and also to give suitable assistance, first, in the discovery of contagious and epidemic diseases and, next, in the production of accurate lists of deaths.

This canon of objectives, fulfilled by determining the occurrence, cause and time of death - together with an assessment of the manner of death and information as to whether or not any contagious disease, as defined by the infection protection act of the relevant country, is present - have remained unchanged until the present day. The terminology for death certification can be found in Table 6.2.

The first and most important purpose of the external postmortem examination is the determination of death not only in the interest of the decedent but also as a social requirement.

A safe determination of cause of death and underlying disease is also of utmost priority. Mortality statistics and resource sharing in the health care system are both based on data about underlying disease and cause of death. An exact definition of the manner of death is essential to guarantee legal certainty but may also have consequences for other legal areas (e.g. civil law, insurance law, compensation law).

The legal bases for external postmortem examinations vary from country to country, and even between different counties of the same country. In Germany for instance, each of the 16 counties has its own funeral law. An external postmortem examination has to be carried out once a dead body is found. A human corpse is defined as follows:

1. The body of a dead person, as long as tissue continuity has not been destroyed by putrefaction.

2. The body of a dead neonate (irrespective of the body weight) if it has completely left the womb, and if after leaving the womb it showed one of the three signs of life (heartbeat, umbilical pulsation, breathing).

3. A stillbirth (stillborn baby weighing $\geq 500 \mathrm{~g}$ ).

4. The head or torso separated from a body that cannot be reassembled.

The following are not corpses:

1. Skeletons, partial or complete.

2. Miscarriages (stillborn fetuses with a birth weight $<500 \mathrm{~g}$; no requirement to report the death).

The body should be examined without delay once notice of the death has been received. Any physician may certify a death, but in some counties in Germany a physician who is related to the diseased may not be allowed to certify a death. Every private practice physician in the area covered by his or her practice, and in hospital, has the obligation to certify a death. A careful examination of the completely unclothed body is mandatory. 
Table 6.1 Function and importance of the external postmortem examination. Reproduced with permission from Madea (2006), (C) Springer.

$\begin{array}{ll}\begin{array}{l}\text { Function } \\ \text { Importance }\end{array} & \begin{array}{c}\text { Social and individual interests in correct determination of death, ending of the normative } \\ \text { protection of life, civil registers }\end{array} \\ \begin{array}{l}\text { Determination of the cause of death } \\ \text { care system, development of public health programs, allocation of health care resources } \\ \text { Legal security, detection of homicides, classification of conditions of death on requests by } \\ \text { civil law, insurance law or compensation law }\end{array} \\ \begin{array}{l}\text { Determination of time of death } \\ \begin{array}{l}\text { Civil registers, inheritance law } \\ \text { infection protection act }\end{array} \\ \text { Obligations to report }\end{array} \quad \begin{array}{l}\text { Hygienic aspects as social interest } \\ \text { If the manner of death is unnatural/undetermined } \\ \text { If the identity of the deceased is unknown } \\ \text { According to the infection protection act }\end{array}\end{array}$

Table 6.2 Terminology of death certification. Reproduced with permission from Myers and Farquhar (1998), () Canadian Medical Association.

\begin{tabular}{|c|c|}
\hline Term & Definition \\
\hline Certifying physician & $\begin{array}{l}\text { Physician completing cause of death statement on the death certificate (may be the } \\
\text { attending physician, his or her delegate, or the coroner) }\end{array}$ \\
\hline Cause of death statement & Completion of part I and II of the death certificate \\
\hline Underlying cause of death & $\begin{array}{l}\text { The condition that triggered the chain of events leading to death; temporally the most } \\
\text { remote condition; aetiologically specific }\end{array}$ \\
\hline Immediate cause of death & $\begin{array}{l}\text { The final complication resulting from the underlying cause of death, occurring closest to the } \\
\text { time of death and directly causing death }\end{array}$ \\
\hline $\begin{array}{l}\text { Antecedent ('intervening' or } \\
\text { 'intermediate') cause of death }\end{array}$ & $\begin{array}{l}\text { A disease or condition that occurred as a result of the underlying cause of death but was not } \\
\text { the final complication or immediate cause of death }\end{array}$ \\
\hline Mechanisms of death & $\begin{array}{l}\text { Physiological derangements or biochemical disturbances by which a cause of death exerts its } \\
\text { lethal effect(s) (e.g. cardiac arrest, respiratory arrest); must not be used as an underlying } \\
\text { cause of death }\end{array}$ \\
\hline Non-specific condition & $\begin{array}{l}\text { An anatomical or functional derangement that has more than one possible cause (e.g. sepsis, } \\
\text { haemorrhage, heart failure, renal failure); must not be used as an underlying cause of death }\end{array}$ \\
\hline Manner of death & $\begin{array}{l}\text { A classification of death based on the type of conditions that caused death and the } \\
\text { circumstances under which they occurred (e.g. natural (due solely to disease), homicidal, } \\
\text { suicidal, accidental or undertermined) }\end{array}$ \\
\hline
\end{tabular}

Careless examination of a body may constitute a regulatory offence. If living people are injured as a consequence of careless medical examination of a dead body, charges may be made against the physician in charge (if, for instance, carbon monoxide poisoning is overlooked and other people also sustain intoxication by carbon monoxide). Emergency doctors may complete a preliminary death certificate only, as the regular external examination has to be carried out by another doctor.

Cases in which the manner of death is unnatural, unexplained or where the identity of the body is unknown have to be reported to the police. All cases that fall under the infection protection act of the country have to be reported to the local health office. All doctors who have previously treated the deceased have to provide the necessary information if asked to do so.

\subsection{Cause of death}

In the confidential part of the death certificate, under the heading 'Cause of death', the course of the disease has to be 


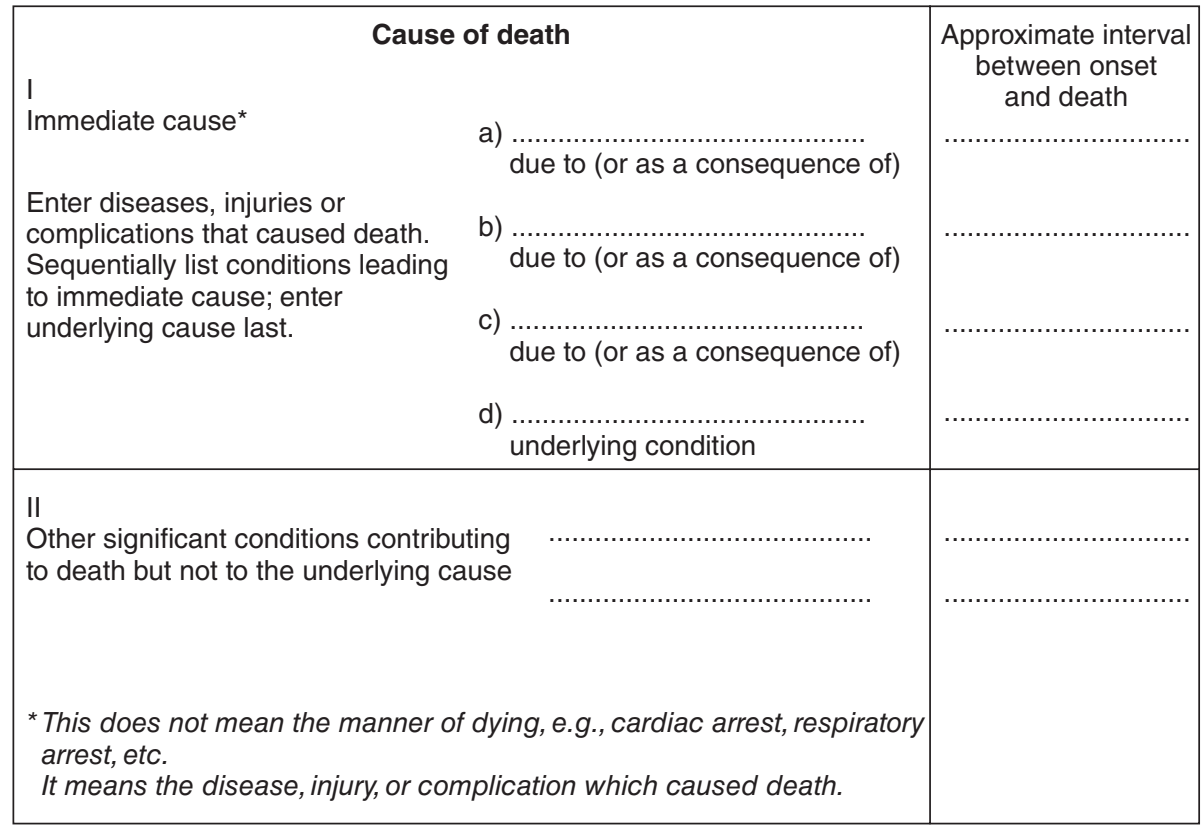

Figure 6.1 International form of medical certificate of cause of death.

documented within a causal chain (Fig. 6.1). The immediate cause of death is given in Part Ia of the document and the preceeding causes - diseases that resulted in the immediate cause of death - in Parts Ib and Ic, with the underlying disease(s) appearing last. Finally, other important diseases that contributed to death but are not linked to the underlying diseases have to be mentioned in Part II. The most important epidemiological information is derived from the underlying cause of death which is used for the purposes of mortality statistics.

The greatest significance of the cause of death is a statistical one: how many people die from a certain disease? This is opposed to the final cause of death which gives information about what people who are suffering from a particular disease actually die of.

According to German Federal Statistical Office recommendations, if nothing precise is known, the entry 'cause of death unknown or unascertained' is preferable to vague speculation. Under no circumstances should constituent elements of every death process, such as 'cardiac arrest', 'respiratory arrest' or 'electromechanical decoupling', be included in any part of the cause of death cascade extending from underlying disease to the immediate cause of death.

Within the right-hand column of the document, the duration (time interval) of the disease is recorded, taking as a starting point the estimated onset of the disease and not the time of its diagnosis. The entries on time intervals also work as a plausibility check on the cause of death cascade. For adequate certification of the cause of death, knowledge of the medical history of the patient and the circumstances leading to her or his death are essential. A careful analysis of the correlation between medical history and medical treatment may already provide important information for the cause of death certification. If the deceased is not personally known to the certifying physician, appropriate information is required from the treating physician.

A formal and correctly arranged cascade for mortality statistics that leads from the direct cause of death to the underlying disease(s) would be for example:

Ia. Oesophageal varicosal bleeding as consequence of $\mathrm{Ib}$.

Ib. Backflow within the portal vein.

Ic. Liver cirrhosis (underlying disease).

II. Diabetes mellitus.

Ia. Retention pneumonia.

Ib. Obturating bronchial carcinoma.

\section{Case example 1}

A 63-year-old man with chronic duodenal ulcer dies several days following surgery for duodenal perforation of postoperative peritonitis. Furthermore, he suffered from bronchial carcinoma. A correctly arranged cascade from cause of death to the underlying diseases is:

la: Peritonitis.

lb: Perforation of duodenal ulcer with postoperative peritonitis (1 week).

Ic: Chronic duodenal ulcer (4 years).

II: Bronchial carcinoma of the lower lobe of the left lung.

If the patient would not have died of postoperative peritonitis due to chronic duodenal ulcer he would have lived to die a few years later of bronchial carcinoma. 


\section{Case example 2}

A 41-year-old patient developed an apallic syndrome after an anaesthetic misadventure. He died of pneumonia 4 years later. A correctly arranged cascade from cause of death to the underlying diseases is:

la: Pneumonia.

Ib: Apallic syndrome.

Ic: Anaesthetic misadventure.

The manner of death is 'unnatural' in this case.

\section{Case example 3}

A 74-year-old woman suffered a fracture of the femoral neck due to an accidental fall at home. Because she had a cerebral thrombosis several years before, she suffered from hemiparesis. During immobilisation a hypostatic pneumonia developed and she died of pneumonia. A correctly arranged cascade from cause of death to the underlying diseases is:

la: Hypostatic pneumonia.

Ib: Immobilisation.

Ic: Pertrochanteric femoral fracture.

Id: Accidental fall at home.

II: Hemiparesis after cerebral thrombosis (2 years).

The manner of death is 'unnatural' in this case.

If the cause of death given in Ia is not the consequence of further complications or underlying diseases known from the patient's history, no further entries are needed, for example:

Ia: Cranial gunshot wound.

Final indirect causes of death can be divided into organ-related ones and those that are not organ related (Table 6.3).

Within the prestructured entries on underlying disease and cause of death on the death certificate, according to the guidelines of the World Health Organization, physicians should mentally review the entire history of their patient's illness. In particular, they should ask themselves whether or not such a final morbidity was present that would be expected to lead to the patient's death at the time given in the circumstances described.

'Hard' and 'soft' causes of death should be distinguished: hard causes of death are present when the underlying disease of death and immediate cause of death are closely related, do appear in a close sequence in time, and when there is a close causal relationship between them, as for example in a case of clinically diagnosed myocardial infarction resulting in cardiac rupture and hence in pericardiac tamponade. In this case, underlying disease and immediate cause of death are present within one organ system (linear type of death).

Soft diagnoses are characterised by patients who suffer from more than one underlying disease, none of which suggests itself a priori as the cause of death, so that the cause of death remains multifactorial.

When evaluating disease conditions regarding their potential as a cause of death, it is helpful to use a classification of findings that has been common in forensic medicine for over a century.
- Group 1. Findings that, because of their severity and localisation, are sufficient in themselves to explain the death of a person without further qualification (e.g. ruptured basilar artery aneurysm with fatal subarachnoid haemorrhage).

- Group 2. Organ changes that explain the death but not the acuity with which it occurred. One example would be acute coronary insufficiency. The morphological substrate, severe atherosclerosis, undoubtedly existed on the previous day, but an external stress such as physical labour in sultry weather was the added external event that led to the onset of death at the given time.

- Group 3. Deaths for which no explanation is found despite the most careful examination.

In addition, one may be guided by 'death types' that have been described as a 'thanatological bridge' between the underlying disease and the immediate cause of death (Fig. 6.2):

1. Linear type of death: underlying disease and immediate cause are within one organ system.

2. Diverging type of death: organ-specific underlying cause, but non-organ-specific immediate cause.

3. Converging type of death: underlying diseases in various organ systems lead to death via a final pathogenetic phase common to all of them.

4. Complex type of death: underlying diseases in various organ systems with more than one non-organ-specific immediate cause of death.

If the cause of death remains unclear in a case of unexpected death of a healthy person, this should be noted on the death certificate. The German Federal Statistical Office recommendations on entering the cause of death and important terms are shown in Table 6.4. When only insufficient information is available to describe the immediate cause of death (e.g. because the patient did not seek medical attendance), descriptive statements should be used such as 'prostatic carcinoma with lung and bone metastases' or 'found dead with a history of severe coronary atheroslerosis and recent myocardial infarction'.

Typical errors in death certificates are summarised in Table 6.5, a case illustration with various errors is given in Table 6.6.

Finally, particular problems arise with deaths in old age or in connection with medical procedures. 'Senility' or 'old age' are not causes of death. Retrospective examinations of deaths of over 85 year olds and over 100 year olds have shown that in each case morphologically ascertainable underlying diseases and immediate causes of death were present. If appropriate, the diagnosed diseases that contributed to the occurrence of death may be descriptively listed as a multifactorial converging type of death, in order to avoid 'makeshift' diagnoses.

Regarding deaths attributable to medical procedures, the first notable point is a considerable discrepancy between the deaths recorded in the German federal statistics as due to complications of medical and surgical treatment and the data derived from epidemiological research on death cases due to maltreatment. 
Table 6.3 Final indirect causes of death. After Fyerter in Madea (2006), @ Springer.

\begin{tabular}{|c|c|}
\hline Cause of death & Examples \\
\hline \multicolumn{2}{|l|}{ Organ-related causes of death } \\
\hline Respiratory organs & $\begin{array}{l}\text { Pneumonia, pulmonary gangrene, pleuritis, pleural emphysema, pneumothorax, } \\
\text { pyopneumothorax, infarction }\end{array}$ \\
\hline Cardiovascular organs & $\begin{array}{l}\text { Coronary thrombosis, pericardiac tamponade, coronary insufficiency, myocarditis, } \\
\text { myocardial infarction } \\
\text { Organic diseases of the heart, e.g. endocarditis, cardiac hypertension, cardiac hypertrophy } \\
\text { with mesaortitis, cor pulmonale, calcific constrictive pericarditis (concretio cordis), } \\
\text { cardiac insufficiency }\end{array}$ \\
\hline $\begin{array}{l}\text { Central nervous system: cerebral } \\
\text { death }\end{array}$ & $\begin{array}{l}\text { Brain haemorrhage, encephalomalacia, cerebral contusion, cerebral swelling, cerebral } \\
\text { oedema, encephalitis, status epilepticus, leptomeningitis, pachymeningitis, subdural } \\
\text { haematoma, epidural haematoma }\end{array}$ \\
\hline Gastrointenstinal tract & $\begin{array}{l}\text { lleus, peritonitis. In children: gastroenteritis, enterocolitis, poisoning, dyspepsia, dystrophy, } \\
\text { atrophy }\end{array}$ \\
\hline Liver & Hepatic coma \\
\hline Pancreas & Diabetic coma, hypoglycaemic coma, haemorrhagic pancreatic necrosis \\
\hline Kidneys & Uraemia, urosepsis \\
\hline \multicolumn{2}{|l|}{ Non-organ related causes of death } \\
\hline Fatal embolisms & Thromboembolism, especially pulmonary embolism, fat embolism, air embolism \\
\hline Bleeding, internal and external & Haemoptysis, melaena, haemothorax, haemoperitoneum \\
\hline Sepsis & $\begin{array}{l}\text { As sequelae of phlegmons and the like, pyaemia, generalised miliary tuberculosis, } \\
\text { urosepsis; see also uraemia }\end{array}$ \\
\hline Tumours & Tumour-associated cachexia, tumour-associated anaemia \\
\hline \multicolumn{2}{|l|}{ Special final indirect causes of death } \\
\hline Malformations incompatible with life & Cerebral aplasia, anencephaly \\
\hline $\begin{array}{l}\text { Special causes of death in fetuses } \\
\text { and newborns }\end{array}$ & $\begin{array}{l}\text { Intrauterine asphyxia with/without aspiration of amniotic fluid, chorioamnionitis, dystrophy } \\
\text { in the premature newborn }\end{array}$ \\
\hline
\end{tabular}

Epidedemiological research for Germany revealed that 17500 deaths per year are suspected to be the result of medical malpractice - these figures are consistent with international data - whereas the Federal Statistical Office mentions 399 deaths only as complications of medical and surgical treatment in 2007. It appears clear that there exists a considerable number of unreported cases, raising the question of whether in relevant circumstances the attending physician should issue the death certificate, or whether, irrespective of the existence or otherwise of suspicion, such cases should always be subject to an official investigation.

\subsection{Causes of death as shown by cause of death statistics}

In 2007, 818271 deaths were reported in Germany; according to the Federal Statistical Office, in 784962 of these, the causes of death were natural. Even just for the location where death occurred, there are no uniform data for the whole of Germany; but more than $50 \%$ of deaths today occur in hospital (according to own data), about $25 \%$ at home and around $15 \%$ in care homes. The remaining $10 \%$ are divided up among transport accidents, work accidents, and so on.

In 2007, of 17178573 inpatient admissions, 6092198 of these were cases belonging to the field of internal medicine. The second largest number of admissions - 3592386 patients were to departments of surgery. Within internal medicine departments, most deaths were seen in cardiology, followed in descending order by gastroenterology, haematology and geriatrics. Out of a total of 818271 deaths in 2007, 258684 were due to cardiovascular conditions, most common of which was 'ischaemic heart disease' (148641 deaths). The second most common group of causes of death was 'malignant neoplasms', with 211765 deaths. It should be borne in mind that deaths for the various disease groups vary considerably among different age groups. 


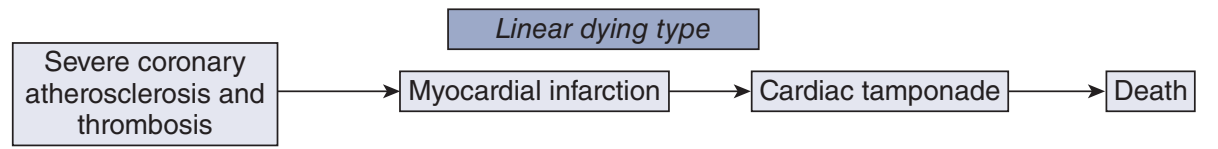

Linear dying type with a vascular disease and cardiac cause of death, 75-year-old male

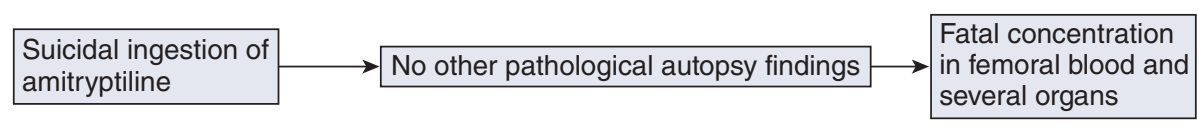

Linear dying type with a drug overdose as cause of death, 43-year-old female

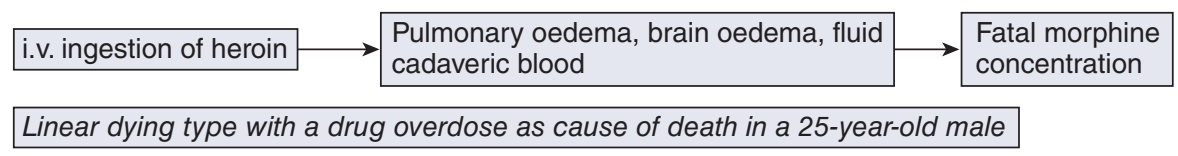

Diverging dying type

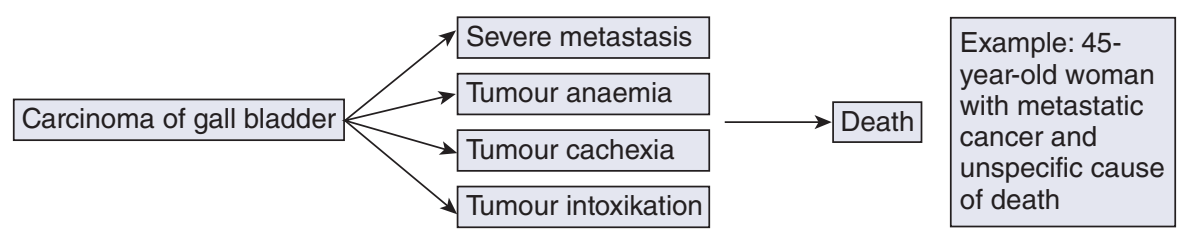

Converging dying type

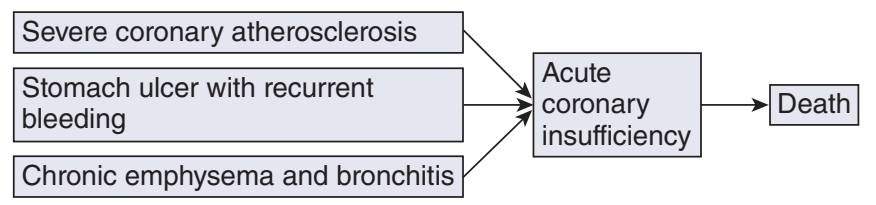

Complex dying type

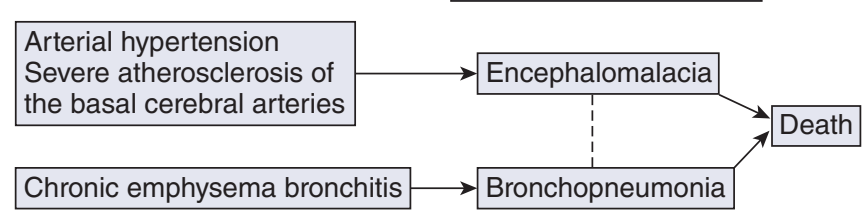

Example: 79-yearold man with vascular, gastric and pulmonary disease

Example: 63-yearold man with vascular and pulmonary disease - cerebral as well as pulmonary cause of death

Figure 6.2 Types of death. After Leis (1982) and Thieke and Nizze (1988); case examples reproduced with permission from Thieke and Nizze (1988) and Madea (2004).

Up to the age of 40 years, unnatural death is more frequent than death from natural diseases (internal cause of death), but beyond this age, deaths from malignancies and cardiovascular diseases become more frequent than unnatural deaths.

These data from the German Federal Statistical Office are taken from the coding of the entries in the death certificate on the underlying disease(s) and immediate causes of death, and it is only the underlying disease which is taken into account in the current cause of death statistics. On the contrary, in the
State (Land) Statistical Offices, the statement on the underlying disease is not automatically used for the cause of death statistics but the coders examine the entries on each death certificate, determine the underlying disease and code this underlying disease in accordance with the International Classification of Diseases regulations. Against the background of increasingly multifactorial death processes, however, monocausal representations of death can only partially fulfil the requirements of cause of death statistics and the data derived from them about indicators for health. 
Table 6.4 Causes of death: examples and important aspects, according to the German Federal Statistical Office recommendations.

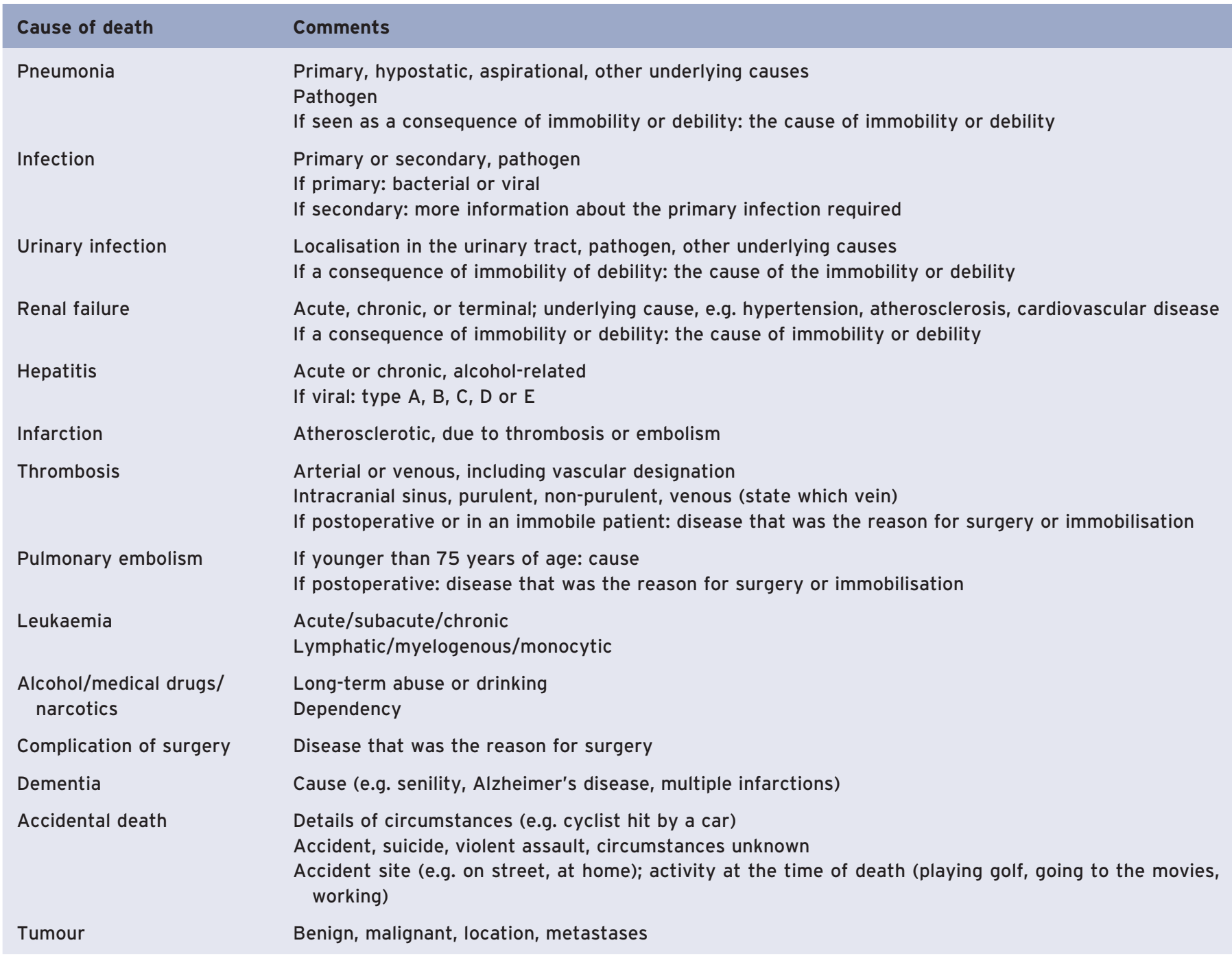

Table 6.5 Definition of major and minor errors in death certificates. Reproduced with permission from Myers and Farquhar (1998), (c) Canadian Medical Association.

Type of error Definition

\section{Major}

Mechanisms of death listed without an underlying cause

Improper sequencing

Competing causes

Minor

Abbreviations

Absence of time intervals

Mechanism of death followed by a legitimate underlying cause of death
Mechanisms or non-specific conditions listed as the underlying cause of death

Sequence of events does not make sense; underlying cause of death not listed on the lowest completed line in part I

Two or more causally unrelated, aetiogically specific diseases listed in part I

Abbreviations used to describe diseases

No time intervals listed in part I or II

Use of a mechanism, but qualified by an aetiologically specific cause of death 
Table 6.6 Case illustration showing types of mistake in stating the cause of death. Case scenario adapted with permission from Myers and Farquhar (1998), (c) Canadian Medical Association.

A 75-year-old male smoker with a 5-year history of pulmonary emphysema is admitted to hospital because of an exacerbation of his lung disease. In hospital, Haemophilus influenzae pneumonia is diagnosed. Independently of this, he has a 10-year history of coronary heart disease. While in hospital his condition worsens, but he does not wish to be intubated and artificially ventilated. One week after admission, he is found dead in his bed. Four alternative ways of staging the cause of death on the death certificate are shown (A-D). In this case only alternative $D$ is correct.

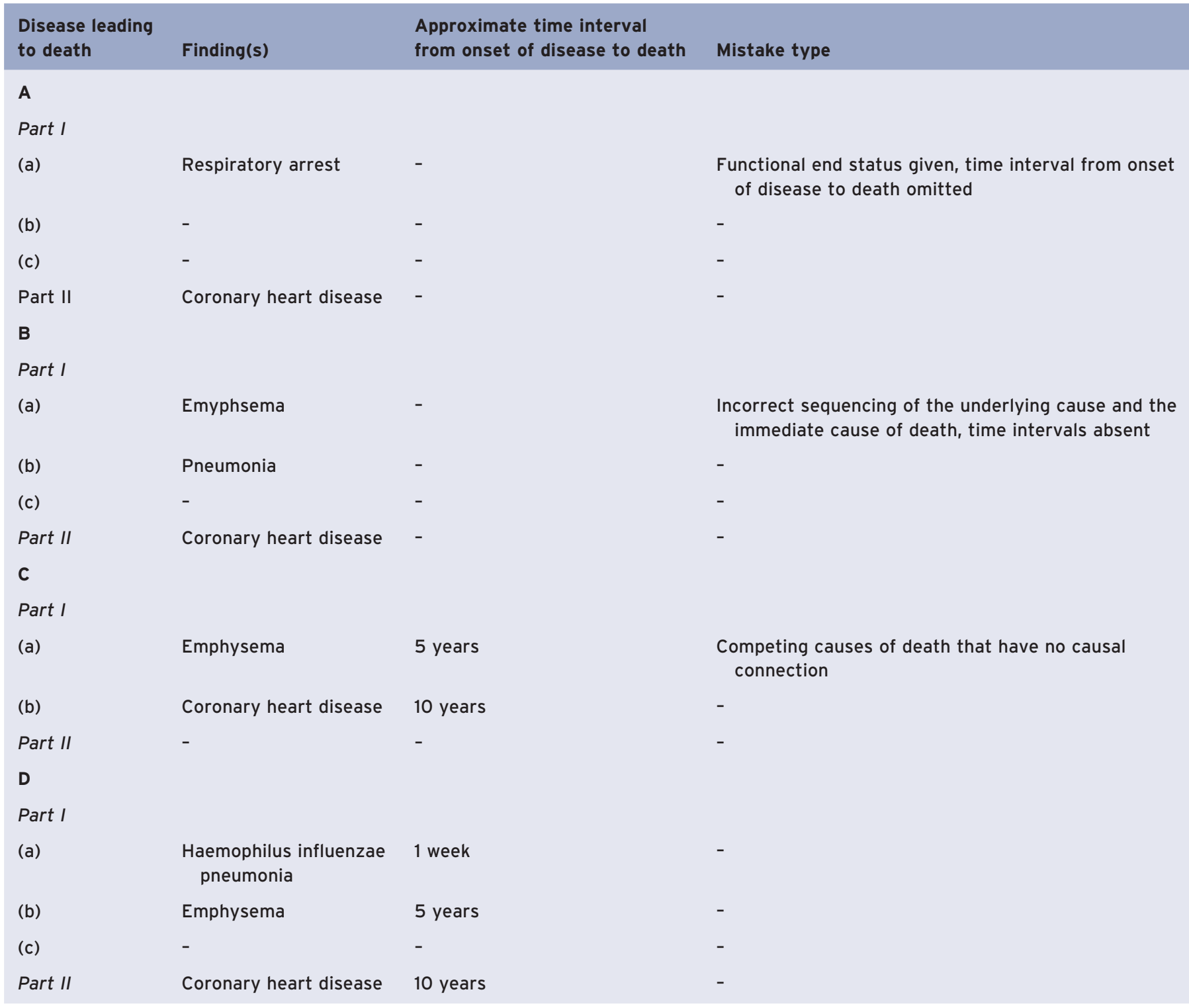

\subsection{Consistency between cause of death diagnosis on the death certificate and following autopsy}

Numerous studies have been published on the validity of clinically determined causes of death as entered on the death cer- tificate in comparison to pathoanatomical findings. The Görlitz study (1986-1987), with a nearly $100 \%$ autopsy rate (1060 deaths, in 1023 of which a postmortem was carried out), showed incongruity between certificate and autopsy findings in totals of $45 \%$ of male deaths and $48.8 \%$ of female deaths. Among hospital deaths, there were incongruities of the underlying disease in $42.9 \%$ of men and $44 \%$ of women; among 
Box 6.1 Discrepancies between causes of death determined clinically and at autopsy. After Shojania et al. (2002).

\section{Major mistake, class 1}

Clinically missed diagnosis that proves at autopsy to have been the underlying cause of death and/or the main immediate cause of the patient's death. If the diagnosis had been made on time, the patient's life could have been prolonged, at least for a time

Major mistake, class 2

Clinically missed diagnoses that would not have affected the management and course of the disease had it been made before death

\section{Minor mistake}

Diseases or medical facts discovered during autopsy that have no direct causal connection with the underlying or immediate cause of death

deaths in care homes the corresponding figures were $63.2 \%$ of men and $57.8 \%$ of women; and for deaths occurring elsewhere (at home, in public, etc.), the rates were $41.3 \%$ for men and $50.7 \%$ for women. Among iatrogenic deaths, the rate of incongruities between underlying diseases as determined clinically and found at autopsy was as high as $72 \%$, and inconsistencies for immediate causes of death were $45.8 \%$.

Numerous studies have differentiated and operationalised the discrepancies between clinically determined causes of death and those determined at autopsy (major mistake, class 1; major mistake, class 2; minor mistake; Box 6.1). According to various statistics, class 1 major mistakes having consequences for treatment and survival of the patient, occur in $11-25 \%$ of all deaths, while class 2 major mistakes, with no consequences for treatment and survival, are found in $17-40 \%$ of all death cases.

According to a meta-analysis by Shojania et al. (2002), class 1 major mistakes have decreased in the past 40 years but do still occur in about $8-10 \%$ of deaths. However, the rate of agreement or disagreement between clinically and autopsy-determined causes of death depends on many variables, such as:

1. The definition of the cause of death.

2. The evaluated disease class.

3. Age.

4. The patient group under investigation (outpatient, inpatient, specialised hospital).

5. The duration of the hospital stay.

6. The predictability of the death (expected vs. unexpected).

7. The autopsy rate.

No comparison between clinically and autopsy-determined causes of death taking into account these variables in a differentiated way have yet been carried out, and none is to be expected under the current regulatory framework (at least in Germany) on performing clinical autopsies. This is particularly true for outpatient deaths, which are almost never subjected to autopsy except when ordered by the courts.
The concept of diagnostic error would correspond to the class 1 major mistake. A diagnostic error is assumed to have occurred when, at the end of the diagnostic decision process, a disease is definitely presumed to be present in a patient when in fact it later proves not to be so. Furthermore, when a treatment is initiated that is not appropriate for the disease identified at the later date, and the failure to recognise the disease that is actually present has led to a worsening of the patient's prognosis, diagnostic error is assumed.

\subsection{Manner of death}

According to cause of death statistics, around $4 \%$ of deaths in Germany result from unnatural causes (Fig. 6.3). Around 10000 cases per year are due to suicides, 6000 to accidents at home, just under 6000 result from transport accidents and 526 deaths result from physical assaults.

Retrospective analyses of death certificates for which the manners and causes of death have been checked at autopsies suggest that unnatural deaths are around $33-50 \%$ more frequent than is reflected by the Federal Statistics, and that it could be assumed that there are around 81000 unnatural deaths every year. From the judicial point of view, a particular concern has to be the number of homicides that remain undiscovered by means of medical death certification. A multicentre study suggests that every year around 1200 homicides remain unidentified on death certificates in Germany (Brinkmann 1997). This large number of unrecorded cases was repeatedly confirmed by incidental findings of homicide or even serial murders (including those in care homes and hospitals). Six per cent of hospital physicians regularly attest exclusively a natural death; $30 \%$ tick the box for natural death even in cases of violence, poisoning, suicide or following medical intervention. In assessing the manner of death, the certifying physician decides whether a death will ever come to the attention of the investigating authorities. Assessing the manner of death is thus an extremely important task not only from the judicial point of view (detection of homicides), but also in terms of the interests of the bereaved (for example, compensation claims after a fatal accident). 'Natural' is a death from an internal causes (disease), where the deceased person has suffered from a disease that can precisely be identified and from which death was anticipated; the death occurred entirely independent from any external factors of legal significance. The prerequisite for attesting a natural death is thus the existence of an underlying disease of death known from the patient's medical history with a poor prognosis as to survival.

'Unnatural', by contrast, is a death attributable to an event caused, triggered or influenced from outside, irrespective of whether it is due to the fault of the patient him- or herself or of a third party. Unnatural deaths are those due to:

- Physical assault.

- Accident (irrespective of whose fault). 


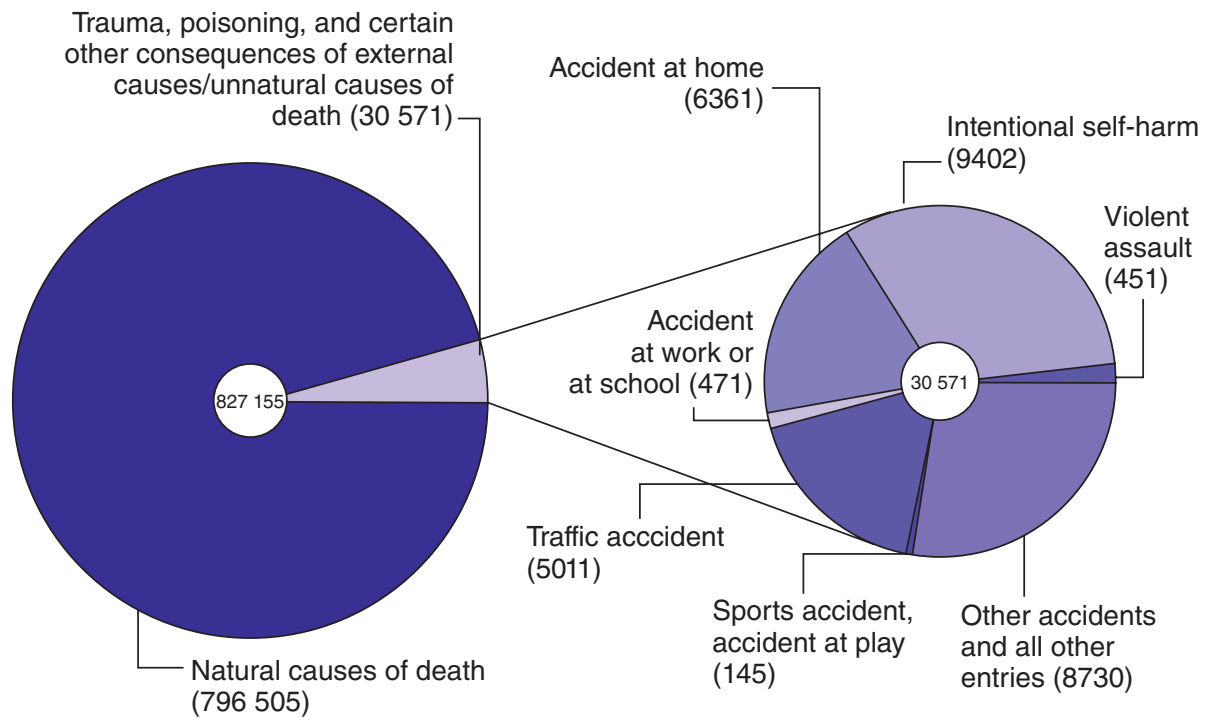

Figure 6.3 Causes of death, showing the proportion of unnatural causes of death among deaths in Germany 2007. Courtesy of the Federal Statistical Office, Germany (www.destatis.de; last accessed 12 June 2013).

- Homicide.

- Poisoning.

- Suicide.

- Treatment errors/medical malpractice.

- Fatal consequences of any of the first six points.

The interval between an external event at the beginning of the causal chain that leads to death and the occurrence of that death can thus be indefinitely long (it may be years). If the cause of death cannot be ascertained when the death certificate is issued, the manner of death will therefore also remain unclear.

Various regulations relating to the certification of death in different states (Länder in Germany), and a draft outline for a federal-wide death certification process from the German Medical Association, envisage explicitly that attestation of a natural death requires examination of the unclothed body. Section 3 of the Bavarian Interment Regulations, for example, says, ... . determination of a natural death requires in every case that the medical external examination on which the death certificate is based be carried out with the body of the deceased completely undressed. This examination of the completely undressed body shall include all regions of the body including all body orifices, the back, and the scalp'.

Sensible though this requirement is, there is no doubt that it is regularly disregarded. If the physician fails to meet the required standards of thoroughness, however, he or she has committed a regulatory offence. Alternatively, it must be recognised that completely undressing a dead body in cases of expected death in hospital will not lead to any gain in further information and can face the certifying physician with objective problems (e.g. when complete rigor mortis is established and no support personnel are available to help). Furthermore, this requirement fails to take into account the difference between expected and unexpected deaths.

The manner of death remains undetermined if the cause of death cannot be identified on examination even with the help of the medical history. The attestation of natural death always assumes that a clear cause of death can be given. In this regard, it is worrying, that about $50-70 \%$ of physicians certify a 'natural' death for death following femoral neck fractures, $20 \%$ for deaths during injections and 30-40\% for intraoperative deaths.

If on the one hand, unnatural deaths are considerably underrepresented in official statistics, and on the other hand, both physicians in private practice and those working in emergency departments report attempts by the police to influence them to certify a death as natural although no cause of death is apparent, hence the death ought to be certified at least as unexplained. In an anonymous survey of randomly selected physicians, $41 \%$ of physicians in private practice and $47 \%$ of emergency room physicians reported such attempts to influence death certification. The background of these attempts is that investigating authorities have a teleologically narrowed understanding of the term 'unnatural death' as meaning 'death in which there is a possibility of third-party guilt'. If a natural death is certified, no further investigations are necessary. Indicators that a death may be unnatural may arise from the case history and findings: for example, sudden death without known previous illness, prima facie accidents and suicides, presence of farewell letters, and so on. Findings that tend to indicate unnatural death include conjunctival haemorrhages, unusual colour of livor mortis, remains of tablets in the oral area and signs of injury. 
Unsuitable criteria for indications of natural death are age, especially when no pre-existing life-threatening diseases are known, and the absence of visible trauma.

Regarding deaths in hospital, especially when the patient was under medical treatment for long enough a period, the error rate should also be relatively low; problem areas include failure to identify causal connections to trauma at the beginning of the fatal causal chain, and deaths related to medical procedures. In the inpatient setting, there are occasional reports of initially unrecognised series of killings by physicians or nursing personnel.

The danger of errors and scope for deception are without doubt greatest when death is certified by private practice physicians at home; typical mistakes and sources of error, in order of frequency, are:

- Inexperience.

- General carelessness.

- Careless examination of the body.

- Consideration of the emotional state of relatives.

Furthermore, there are sometimes also unfavourable external conditions, such as poor lighting, and simply not being adequately trained for the job; or that there was no possibility of calling an appropriately qualified certifying physician. Particularly physicians in private practice can find themselves being confronted with a conflict of interests, since they are also the physician of the relatives of the deceased. Attesting an unexplained death puts them at risk of triggering investigations that could lose the relatives as patients. Compared to a physician working in private practice, the hospital physician is in a more protected position (death in the medically dominated environment of a hospital rather than in the private area).

\subsubsection{Problem areas}

Problems that may repeatedly arise within the hospital context are as follows:

1. Deaths in connection with medical interventions.

2. Deaths following injury from a fall or other violent events, in which the causal connection to violence from another person or another external event is not identified and therefore death is wrongly certified as natural.

For deaths occurring unexpectedly linked to medical interventions, the manner of death should always be certified as 'unexplained', so that an official autopsy can be carried out to investigate objectively the underlying and immediate cause(s) of death. This is the only basis an opinion can be expressed on any question of maltreatment. Certifying the manner of death as unexplained or unnatural does not signify an admission of maltreatment.

For physicians in private practice, the main problems may arise when bodies are found at home, patients die unexpectedly and with deaths occurring in old age.
Box 6.2 Errors and risks of the medical examination for death certification.

Beware

- Never certify a death in the absence of definite sign(s) of death

- Examine the unclothed body carefully

- Review the patient's medical history: What was the clinical diagnosis? What was the sequence of events leading to death? Can manner and circumstances in which death occurred be explained by the confirmed clinical diagnosis?

How certain are the diagnoses of the underlying and immediate causes of death?

- Was there any external event at the beginning of the causal chain that led to death? If yes, the death should be certified as unnatural

- If death occurred in the context of medical interventions, the manner of death is unexplained or unnatural

- If the cause of death cannot be established even after interviewing doctors who previously treated the patient, it remains unclear, and so does the manner of death

- Resist attempts to influence how you complete the death certificate

\section{Mistakes}

- Giving the functional status as cause of death without relating it to an underlying cause

- Incorrect sequence from the final cause of death to the underlying cause

- Time intervals not stated

- Overlooking a causal connection with an external event (e.g. trauma) at the beginning of the causal chain that led to death

- Inadequate or misinterpreted clinical information

- Efforts to conceal diagnoses that might cause uneasiness or distress to family members

If the cause of death cannot be established from external examination of the body or from interviewing any doctors previously involved in treatment, this should be recorded and the manner of death certified as unexplained. With old people, there is always the question whether or not case history and severity of the diagnosed disease(s) explain the occurrence of death at this particular moment. Mistakes and risks of the medical examination of a body are summarised in Box 6.2.

Whenever the cause of death cannot be established by external examination, an autopsy should be carried out, as this is still usual in many countries in Europe. In Germany, the present autopsy rate is less than $5 \%$ of all deaths; the rate of hospital autopsies in particular has been dropping sharply in recent years, while judicial autopsies have remained relatively stable at $2 \%$ of deaths (compared to autopsy rates of $20-30 \%$ in England, Scotland and Wales, Sweden and Finland).

These autopsies, which are required for valid cause of death statistics and for the planned National Mortality Register, would, however, have to be remunerated adequately, which unfortunately they are not at present. 


\subsection{Special constellations of circumstances in external postmortem examination}

\subsubsection{Unexpected deaths during hospitalisation}

About $2-2.5 \%$ of all hospitalised patients die at hospital. In Germany, of 17.5 million hospitalised patients, around 400000 die each year. Death cases are mainly due to severe underlying disease or accidents that have led to hospitalisation. However, unexpected deaths occur in hospital too, due to as yet diagnosed diseases, as for example in acute coronary insufficiency or pulmonary embolism. Special problems include diagnostic or therapeutic misadventures. When unexpected deaths occur during hospitalisation, especially in connection with medical procedures, the manner of death should be classified as unnatural or unascertained and the police should be notified.

Other types of unnatural deaths during hospitalisation are accidental falls, deaths during fixation, scaldings when people are being left unattended in bathrooms and also suicides (in particular in psychiatric hospitals). However, homicides, even serial homicides, occur in hospital, committed by doctors and nurses. Therefore, each case of an unexpected death during hospitalisation requires a thorough investigation.

\subsubsection{Deaths in police custody}

Death in police custody occurs mainly in males within the fourth to fifth decade of life. Causes of death range from sudden natural death (especially due to cardiovascular diseases), to suicide (mostly by hanging), undiagnosed head injuries and intoxications (alcohol intoxication or mixed alcohol-drug intoxication), or combinations of both. Special risk factors for deaths in police custody are higher age, pre-existing natural diseases, injuries, blood alcohol concentrations higher than $300 \mathrm{mg} / 100 \mathrm{~mL}$ and combined alcohol-drug intoxication. Therefore prior to imprisonment a thorough investigation to determine the fitness of the individual to be detained in custody has to be carried out. People under the influence of alcohol may show impaired consciousness. In cases with additional head trauma a differential diagnosis between impaired consciousness due to alcoholisation or head trauma is important.

\subsubsection{Deaths in prison}

Of deaths in prison $30-40 \%$ are due to natural diseases, mostly cardiovascular diseases. Comparatively rare are deaths due to accidents by intoxication. Homicides occur only very rarely. Of greater importance are suicides (mainly by hanging) that are particularly committed by male prisoners in the third decade of life and at the beginning of imprisonment in single cells. Clothing, belts, pieces of bedclothes and electric cables are often used for strangulation and windows and parts of sanitary installations or heating pipes for suspension. Even in prison cells occupied by more than one prisoner unnoticed suicides can occur.

\subsubsection{Deaths in the bathroom}

Unexpected deaths in the bathroom are a particular challenge since only $10-30 \%$ of these cases are due to natural mechanisms. Of particular importance are accidents and suicides, but $5 \%$ of cases are expected to be homicides or around the disposal of a homicide victim in the bathtub. As causes of unexpected deaths, carbon monoxide poisoning, drug intoxication and electric devices being used in the bathtub play important roles. Electric burns may be absent in bathtub deaths. However, porcelain white stripes and a demarcation of postmortem lividity according to the water level may be seen.

Even violent deaths in bathtubs may show only few if any external injuries. In a well-known case of crime history the offender drowned his victims (his wives who trusted him) when they took a bath by taking their legs and pulling them out of the bathtub until their heads were under water. In cases of deaths in the bathroom therefore the following checklist may be helpful.

\section{Findings at the scene}

1. Drugs, sources of carbon monoxide, water in the bathtub (water level, water running, water temperature, bath additives).

2. If the bathtub is empty lines or marks in the bathtub corresponding to the previous water level.

3. Electric devices near to or in the bathtub.

4. Switch position of hairdryers or room heaters.

5. Farewell letters in the premises.

\section{Examination of the corpse}

1. Basic examination: clothing, postmortem lividity, rigor mortis, body core temperature (rectal temperature), water temperature.

2. Signs of water immersion like washer-woman's skin.

3. Signs of drowning (froth extruding from mouth and nose).

4. Findings that are related to possible intoxication.

5. Electrical burns: blisters, 'linear electric burns', linear demarcation of postmortem lividity according to the water level.

6. Death due to pre-existing diseases like epilepsy with seizures (tongue bites).

7. Injuries which are not compatible with the findings at the scene. 


\subsubsection{Deaths in psychiatric hospitals}

There is a higher suicide rate of mentally ill patients, especially due to depressive and schizophrenic disorders, in psychiatric hospitals. They are mainly committed by younger patients in the third to fourth decade of life. Hanging is one of the most frequently used methods followed by intoxication and falling from a height. If suicide by jumping from a height is suspected the horizontal distance between the final position of the body and the point where the person jumped off has to be measured and checked for plausibility.

When thick clothing is worn and the ground is soft there might be a significant discrepancy between the absence of externally visible injuries due to the blunt force impact and extensive injuries revealed at autopsy.

\subsubsection{Deaths at the steering-wheel}

Death at the steering-wheel may be due to accidents, suicides or pre-existing natural disease. Suspicion for suicidal death is raised if the cause of an accident is not evident, for example driving on a straight street at high speed against the pillar of a bridge with the safety belt unused. In case of sudden death behind the steering-wheel, there are often only minor injuries seen on the deceased, and there may be a typical driving pattern, such as striking parked cars, collision with oncoming vehicles, drifting to the opposite lane or attempts to stop the car. Sudden natural death at the steering-wheel mostly affects men within the sixth to seventh decade of life dying due to ischaemic heart disease. Electrophysiologically, fatal cardiac arrhythmia develops over a period of about 2 minutes. Warning symptoms due to damage of cerebral function are recognised and the car driver tries to stop the car to avoid severe accidents. If serious injuries are found following unexplained accidents at external postmortem examination, an autopsy should be carried out to clarify two substantial questions:

1. Is there any internal natural disease that possibly caused the accident?
2. Is there an internal disease that may have contributed to death compared to the accident-related injuries?

\subsubsection{Deaths by poisoning}

The suspicion of poisoning depends on three circumstances: case history, conditions under which death occurred and findings at the external postmortem examination. Intoxication as a cause of death has to be taken into account under the following circumstances:

1. Young healthy people without any medical history.

2. Simultaneous 'sickness' of several people.

3. Mentally ill people.

4. Drug addicts.

5. Third parties that might be interested in the death of an individual (e.g. elimination of a relative who is perceived as a burden for carers, rich testators, high-value of life insurance, enemies, rivals).

6. People who have good access to poisons (e.g. chemists, biologists, physicians, nurses, photographers, goldsmiths, etc.).

Symptoms that may hint at intoxication are:

1. Sudden and unexpected illness, sudden collapse and immediate death.

2. Seizures, agitation, loss of consciousness, coma or sudden unresponsiveness.

3. Respiratory depression, dyspnoea, apnoea or snorkelling.

4. Changes of the diameter of the pupil and salivation.

5. Froth in the mouth and nostrils.

6. Abdominal pain, emesis or diarrhoea.

External findings of the external postmortem examination are mostly non-specific, but there may be certain changes that might indicate intoxication (Table 6.7). Furthermore, great attention should be paid to findings at the scene of death (e.g. glasses or bottles sometimes with remnants of substances, drug containers, warning colours of poisons, vomit, etc.) (Fig. 6.4). Besides poisoning by oral ingestion, poisoning via the vaginal or anal pathway occurs, both in cases of suicides and homicides.

Table 6.7 Findings at the external postmortem examination in cases of intoxication. After Madea (2006), () Springer.

$\begin{array}{ll}\text { Finding } & \text { Possible toxic substances } \\ \text { Skin bleeding } & \begin{array}{c}\text { Each poison that may lead to damage of liver parenchyma, in particular phosphorus, Amanita } \\ \text { phalloides }\end{array} \\ \text { Odour } & \text { Hydrogen sulphide, cyanide, ammonia } \\ \text { 'Holzer' blisters } & \text { Hypnotics (barbiturates) } \\ \text { Miosis }^{\text {a }} & \begin{array}{c}\text { So-called MNOP toxins: morphine, opiates, nicotine, phosphoric acid esters, physostigmine, } \\ \text { pilocarpine, prostigmine, barbiturates }\end{array} \\ \text { Mydriasis }^{\text {a }} & \text { So-called ABC toxins: ethanol, Amanita muscaria, Amanita pantherina, atropine, cannabinoids, } \\ & \text { quinine, cocaine, colchicine, cyanides, methanol, scopolamine }\end{array}$

(Continued) 
Table 6.7 (Continued)

$\begin{array}{ll}\text { Finding } & \text { Possible toxic substances } \\ \begin{array}{l}\text { Acid traces } \\ \text { Salivation }\end{array} & \text { In particular lyes, acids but also halogens, phenol and its derivates, paraquat, trichloroethylene } \\ \text { Light red nails } & \text { Carbon monoxide } \\ \text { Livor mortis: } & \\ \text { ash-grey } & \text { Methanol } \\ \text { brownish } & \text { Methaemoglobin-former (e.g. nitrites, nitrobenzene, chlorates, soaps, aromatic amino } \\ & \text { compounds) } \\ \text { light red } & \text { Carbon monoxide, cyanides } \\ \text { Several injection sites } & \text { Opiates } \\ \text { General icterus } & \text { 'Liver toxins', phosphorus intoxication, mushroom poisoning } \\ \text { Mees' lines } & \text { Arsenic, thallium } \\ \text { Dark gingival seam, stomatitis } & \text { Lead, mercury, bismuth } \\ \text { 'Paw' position of hands } & \text { Hydrocyanic acid, strychnine, phosphoric acid esters } \\ \text { Hair pulls out easily } & \text { Thallium }\end{array}$

${ }^{a}$ Because of agonal (hypoxia of the brainstem) and postmortem changes only of limited value.

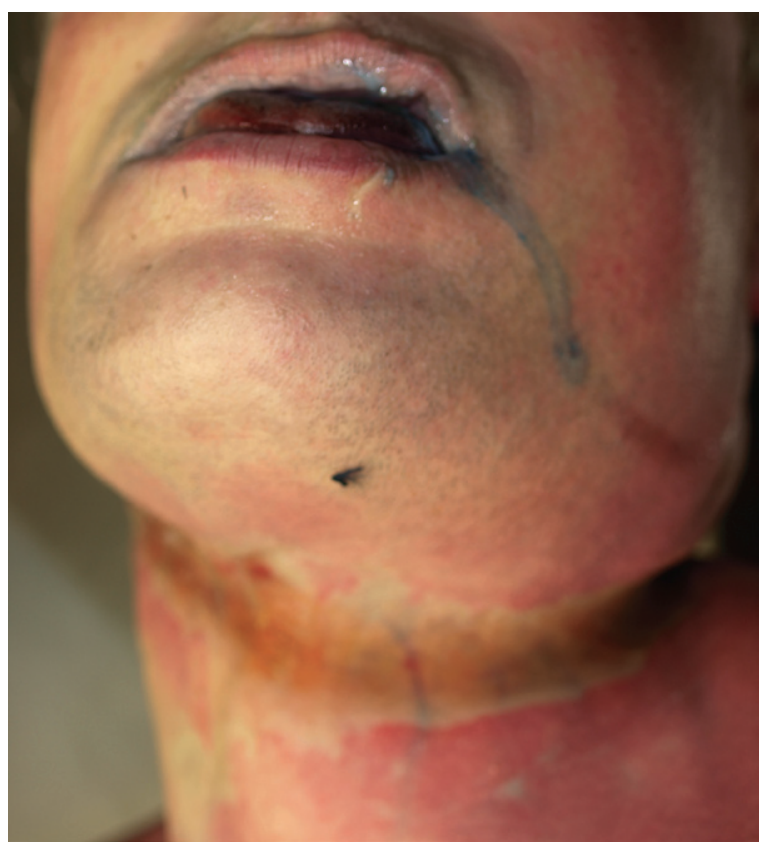

(a)

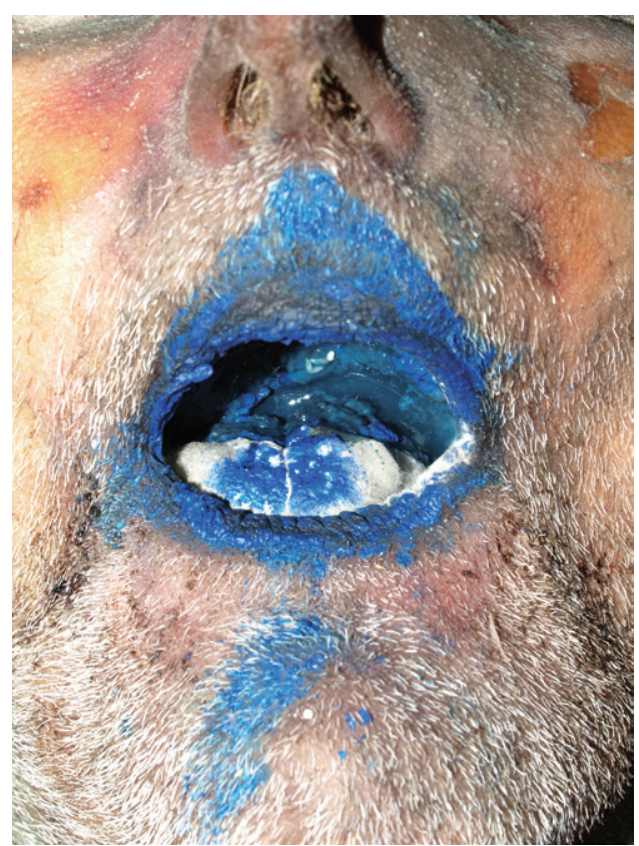

(b)

Figure 6.4 Warning colours in suicidal intoxication. (a) Combined suicide by oxydemetonmethyl ingestion and hanging, as evidenced by the blue stain flow from the left side of the mouth and strangulation mark. (b) Intensive blue colour of mouth and lips in a case of suicidal intoxication with solvents.

\subsubsection{Discovery of several corpses}

If more than one body is found at the scene of death or when a body and a dead animal or a body and another person in poor health are found together, an unnatural death should be assumed unless the contrary is proven. Coincidental deaths of two people at the same time represent an absolutely rare event. When several people are found dead at one scene, the following constellations are possible.

- Homicide.

- Homicide with survivor.

- Homicide with suicide of the offender. 
- Homicide with attempted suicide.

- Suicide, extended suicide, suicide with survivor.

- Accident.

- Death due to underlying natural diseases.

\subsection{Checklist for the external postmortem examination (according to Madea 2006)}

\subsubsection{Who initiated external postmortem examination/who notified doctor?}

1. The bereaved (in cases of death at home).

2. Head of an institution.

3. Medical staff.

4. Failed emergency aid.

5. Police (somebody found dead).

\subsubsection{Date and time of the external postmortem examination}

These should be noted on the patient's medical notes.

\subsubsection{Place of the external postmortem examination}

1. In hospital:

a. death was expected;

b. death was unexpected.

2. At home:

a. death was expected;

b. death was unexpected;

c. discovery of corpses.

3. In public:
a. accident;
b. sudden collapse;
c. emergency aid;
d. discovery of corpses.

\subsubsection{Description of the surroundings where the body was found}

1. Outdoors or indoors (doors and windows opened or closed, describe type and way of locking).

2. Inside and outside ambient temperatures, weather conditions; heating system running or not.

3. Finding of corpses indoors: kind of room, position of the corpse, describe clothing present.

\subsubsection{Description of the immediate surroundings next to the corpse}

1. Condition of the premises (e.g. tidy, neglected, searched, etc.).

2. Information about use of alcohol, illicit drugs or pharmaceuticals (e.g. bottles, cans, drugs, prescriptions, utensils of drug abusers).

3. Weapons, tools for strangulation lying next to the corpse, pools of blood or traces of blood.

\subsubsection{Information about diseases}

Health insurance certificates, drugs or prescriptions.

\subsection{Identification of the corpse}

1. Individual is known to the doctor.

2. Identity documents of the deceased (passport, driving licence) present.

3. Family members/police/others can give information about identity.

4. Identification is impossible.

\subsubsection{Condition of clothing}

1. Arranged or disarranged.

2. Buttons are in buttonholes, buttons are torn out or button tape is damaged.

3. Zippers are unzipped or closed.

4. Kind of outerwear/underwear and footwear.

5. Damage and dirt of clothing and footwear.

6. Stains of blood, secretions on fabric of clothing or tissues.

7. Scratches on footwear/soles.

8. Watches, jewellery and contents of pockets.

9. Modification of clothing during external postmortem examination (clothes are cut, torn).

\subsubsection{Resuscitation}

1. Situation when emergency doctor arrived.

2. Medical actions during resuscitation (see records of rescue services).

3. Injections (note injection sites and differentiate between earlier and recent ones).

4. Intubation (difficulties, complications).

5. External cardiac massage.

6. Complications (rib fractures, misintubation, pneumothorax).

7. Defibrillation. 


\subsubsection{Position of the corpse}

1. Supine position, prone position, lateral position, headdown tilt.

2. Arms/legs stretched, bent, splayed out.

3. Gender, age (estimate if necessary).

4. Body length, body weight, nutritional status.

5. Body adhesions: blood, faeces, sperm, dirt (locations).

6. Trace flow of blood and secretions (course, dried).

\subsection{Examination of the corpse}

\subsubsection{Postmortem changes}

1. Lividity (livor mortis): position, colour (pink, cherry-red: carbon monoxide; cold environment, brownish red: methaemoglobin; normal colour: bluish purplish), intensity, expansion (little expansion: internal/external blood loss; anaemia).

2. Rigidity (rigor mortis): determine the degree of rigor mortis in finger joints and larger joints (present/not present, doughy/smooth, hard, breaking the rigidity manually not possible, reappears after breaking).

3. Drying: of lips, genitals, conjunctivae, extremities.

4. Supravital reactions: determine idiomuscular pad, electric excitation of skeletal muscle, measure deep rectal temperature.

5. Putrefaction: greenish discoloration of abdominal skin, epidermal detachment, skin blisters, facial/abdominal/ scrotal swelling with gas; superficial veins of the skin are visible, putrefactive fluids in mouth and nostrils, hair pulls out easily, nails fall off.

6. Corpse fauna: fly eggs in nostrils, palpebral fissures, corners of the eyes, corners of the mouth or penetrating skin lesions; fly maggots (lengths); fly pupation, pupae; empty pupal shells.

7. Is the degree of postmortem changes compatible with indicated time of death?

\subsubsection{Systematic examination of the corpse}

1. Odour: press on costal arch, take a smell at mouth and nose (alcoholisation: aromatic odour, hydrogen cyanide: bitter almond odour, E605: garlic-like odour; uraemia: acetone)

2. Oedema of the lower legs.

3. Pressure marks on knees/ankles: 'Holzer' blisters in cases of hypnotic intoxication with sedatives and barbiturates.

4. Scars: on the inner wrist if attempted suicide in the past, surgical scars, scars after cut/stab wounds.

5. Injection sites: drug addiction, then check crook of the arm, forearm, back of the hand, but also interdigital skin between fingers and toes, mucosa of the oral vestibule, tongue, groin, penis; older injection sites and injection sites of different ages arranged like Baily's beads ('shoot bands'), skin abscesses or scars thereof.

6. Signs of pregnancy: darker areolae mammae, yellowish fluid running out of mamillae when squeezed, striae on lower abdomen and thighs; palpatory findings over abdomen, fundal height.

7. Hairy scalp palpation: swelling, haematoma, injuries of the scalp, palpable crepitation.

8. Facial: lesions of prominent parts (eyebrows, zygomatic arches, nose, chin - injuries due to falls when sudden death occurred), bleeding, eyelid swelling (monocular haematoma, lips and mucosa of the oral vestibule with lacerations when blunt force impact/beating occurred), bleeding from the external auditory meatus (and/or from the mouth and nose); basilar skull fracture - punctal petechial haemorrhages of the facial skin (on eyelids, in conjunctivae of the eyelids, mucosa of the oral vestibule during compression of the throat (manual strangulation/ ligature), chest compression; detailed examination of the neck necessary in every case.

9. Facial swelling and cyanosis.

10. Eyes:

a. opened, closed, drying of the sclerae;

b. pupil width: of equal or different size, small/middle/ large width;

c. Haemorrhages of the conjunctivae of the eyeballs.

11. Mouth and nose:

a. froth: pulmonary oedema (congestive heart failure), opiate intoxication, drowning;

b. death due to compression of the neck;

c. vomitus in the oral cavity, foreign material in the oral cavity;

d. suicidal or homicidal intoxication: particles of tablets;

e. trace flow from a corner of the mouth, trace flow of saliva in cases of hanging (salivation due to pressure to pterygopalatine ganglion);

f. blood in the oral cavity and in the oral vestibule: blunt force (lacerations of the lips and the mucosa of the oral vestibule);

g. gunshot wound in the mouth;

h. teeth: fixed, condition of denture; acid burn of lips, trace flows;

i. teeth framed prints on lips and the mucosa of the oral vestibule: manual occlusion of the mouth;

j. upper gastrointestinal bleeding: in case of gastric bleeding possibly haematinised blood acid or alkaline intoxication.

12. Tongue: behind, between the rows of teeth, injuries due to bitemarks.

13. Nose:

a. nasal skeleton with abnormal mobility, contents of nostrils, trace flows;

b. perioral/perinasal dryings/reddening of the skin;

c. occlusion of the mouth and nose. 
14. Neck: injuries (dryings, skin bleeding, subhaemorrhages, scratches of the epidermis, tools for strangling found around the neck, ligature furrow, ligature mark): horizontal mark ascending to one side or to the nape of the neck, similar or different ligature impressions, double ligature marks, subcutaneous bleeding in the middle of the ligature mark.

15. Trunk/thorax/extremities:

a. injury signs: dryings, abrasions, haemorrhages, subcutaneous haematomas, penetrating skin lesions, abnormal mobility (cervical spine: pull head gently and turn it to each side);

b. pelvic ring (press/palpate spina iliaca anterior superior and symphysis);

c. arms: fingertip bruising on the inner upper arms, defensive wounds on the extensor side, on forearms (ulnar/little finger side), on the backs of the hands; abrasions on the backs of the hands due to atonic falls; gunshot residues, blood splatters, injuries caused by the slide of a weapon in cases of suicidal gunshot injury.

16. Electric burns: on hands, flexor aspects of fingers, soles, toes.

17. Anus, genitals: anal bleeding, genital bleeding (signs of injury, foreign objects, adhesion of secretion, sperm, faeces).

18. General status of care and nutrition (important in cases of neglect: infants, toddlers, disabled, elderly, invalids).

19. Decubital ulcers, pressure sores: localisation, size, status of care.

\section{Necessary instruments for the external postmortem examination}

1. Single-use gloves.

2. Two forceps (to evert the conjunctivae of the eyelids).

3. Torch light if illumination is low.

\subsubsection{Anamnesis/conditions of death and time of death}

1. Death was expected, defined underlying disease with a poor prognosis was known; time and conditions of death is compatible with diagnosis and prognosis.

2. Sudden and unexpected death; no anamnestic information regarding underlying diseases that could directly lead to death.

\subsubsection{Who performed the external postmortem examination}

1. Treating physician.

2. Doctor with information given by treating physicians.
3. Neutral doctor when death occurred during surgery (exitus in tabula).

4. Doctor with no information given by treating physicians.

\subsubsection{Measures/consequences}

1. When external postmortem examination is completed, the death certificate has to be filled out (ask treating physician if additional information is available on the case medical history).

2. If it is impossible to undertake the external postmortem examination at the place where the corpse was found: inform the police.

3. If death is unnatural or manner of death is unclear: inform police.

4. If there is suspicion of carbon monoxide intoxication, inform residents and police in order to determine the source.

\subsection{Completing the death certificate}

1. Functional final states (such as respiratory, circulatory or cardiac arrest, cerebral death, old age) are not 'causes of death' but constituent parts of the dying process.

2. Cachexia and bleeding to death are causes of death but the underlying diseases have to be named such as:

a. cachexia caused by anorexia nervosa;

b. bleeding to death caused by an aneurysm that ruptured into the abdominal cavity;

c. bleeding to death caused by stab wounds of the chest with injuries of heart and lungs.

3. Note obligation to inform the:

a. police: if death is unnatural, the manner of death is unclear or the identity of the deceased is not known;

b. health authority: if there is suspicion of communicable diseases and/or transmitted diseases according to the infection protection act.

\section{Useful website}

Statistisches Bundesamt, www.destatis.de (last accessed 18 March 2013).

\section{References and further reading}

Berzlanovic, A., Keil, W., Waldhoer, T., Sim, E., Fasching, P. \& FazenyDörner, B. (2005) Do centenarians die healthy? An autopsy study. Journal of Gerontology 60, 862-5. 
Brinkmann, B. (1997) Fehlleistungen bei der Leichenschau in der Bundesrepublik Deutschland. Ergebnisse einer multizentrischen Studie (I) und (II). Archiv Kriminologie 199, 2-12, 65-74.

Burton, J.L. (2007) The external examination: an often neglected autopsy component. Current Diagnostic Pathology 13, 357-65.

Burton, J.L. \& Rutty, G.N. (2010) The Hospital Autopsy, 3rd edn. London: Hodder Arnold.

Ferris, J.A.J. (2005) Autopsy. Adult. In: Payne-James, J., Byard, R.W., Corey, T.C. \& Henderson, C. (eds) Encyclopedia of Forensic and Legal Medicine, Vol. 1, pp. 183-92. Amsterdam: Elsevier.

Hanzlick, R. (1993) Death certificate. The need of further guidance. American Journal of Forensic Medical Pathology 14, 249-52.

Hanzlick, R. (2007) Death Investigation - Systems and Procedures. Boca Raton, FL: CRC Press.

Interpol (2002) Diseaster Victim Identification Form. http://www .interpol.int/Public/ICPO/FactSheets/FS02.pdf (last accessed 18 March 2013).

Junbelic, N.I. (2005) Mass disasters. Role of forensic pathologists. In: Payne-James, J., Byard, R.W., Corey, T.S. \& Henderson, C. (eds) Encyclopedia of Forensic and Legal Medicine, Vol. 1, pp. 197-207. Amsterdam: Elsevier.

Leis, J. (1982) Die Todesursache unter indivudal-pathologischen Gesichtspunkten. Deutsche Medizinische Wochenschrift 107, 1069-72.

Madea, B. (2006) Die ärztliche Leichenschau. In: Rechtsgrundlagen Praktische Durchführung - Problemlösungen, 2nd edn. Berlin: Springer.

Madea, B. (2007) Praxis Rechtsmedizin. Befunderhebung, Rekonstruktion, Begutachtung, 2nd edn. Berlin: Springer.
Madea, B. \& Kernbach-Wighton, G. (2012) External postmortem examination. In: Saukko, P. \& Siegl, J. (eds) Elsevier Encyclopedia of Forensic Sciences, 2nd edn. Amsterdam: Elsevier.

Madea, B. \& Rothschild, M. (2010) The postmortem external examination. Deutsches Ärzteblatt International 107(33), 575-88 .

Magrane, B.P., Gilliland, G.F. \& King, D.A. (1997) Certification of death by family physicians. American Family Physician 56, 1433-8.

Maudsley, G. \& Williams, E.N. (1996) Inaccuracy in death certification - where are we now? Journal of Public Health Medicine 18, 59-66.

Myers, K. \& Farquhar, D.R.E. (1998). Improving the accuracy of death certification. Canadian Medical Association Journal 158, 1317-23.

Pounder, D., Jones, M. \& Peschel, H. (2011) How can we reduce the number of coroner autopsies? Lessons from Scotland and the Dundee initiative. Journal of the Royal Society of Medicine 104, $19-24$.

Rutty, G.N. (2010) The external examination. In: Burton, J.L. \& Rutty, G.N. (eds) The Hospital Autopsy, pp. 90-103. London: Hodder Arnold.

Shojania, K., Burton, E., McDonald, K. et al. (2002). The Autopsy as an Outcome and Performance Measure. Evidence Report/Technology Assessment No. 58 (prepared by the University of California at San Francisco-Stanford, Evidence-based Practice Center under contract no. 290-97-0013). AHRQ Publication for Health Care Research and Quality.

Thieke, C. \& Nizze, H. (1988) Sterbenstypen: Thanatologische Brücke zwischen Grundleiden und Todesursache. Pathologe 9, 240-4.

Wagner, S. (2009) Death Scene Investigation. A Field Guide. Boca Raton, FL: CRC Press. 